\title{
0 perfil de casais que vivenciam divórcios consensuais e litigiosos: uma análise das demandas judiciais
}

\author{
Eliana Picedi Zordan- UnivesidadeRegional Integada doAltoUnugrai edas Missõess Erehim RioGrandedo Sul, Brasil \\ Adnana Wagner - UnivesidadeFederal doRioGrandedbSul, PatoAlege, RioGrandedoSul, Brasil \\ ClanisseMosmann- UnivesidadedbV aledbRiodos Sinos, SãoLeepddb, Rio GrandedbSul, Brasil
}

\begin{abstract}
Resumo
Este estudo objetivou identificar os motivos, circunstâncias e desdobramentos das separações conjugais com base em registros em processos judiciais. Realizou-se uma análise documental de 152 separaç̃os conjugais arquivadas de 1992 a 2006, no Fórum de uma cidade do interior do RS. Fez-se uma análise descritiva e discriminante dos dados. Os motivos mais citados referem-se ao conflito conjugal em seus diferentes matizes e intensidades. Quanto ao desfecho, constatou-se que $46,7 \%$ dos processos foram consensuais, 30,9\% litigiosos e em $22,4 \%$ houve abandono da ação ou reconciliação. 0 perfil dos casais discrimina-se prioritariamente pelo nível socioeconômico no que diz respeito aos processos consensuais ou litigiosos. Separacõos consensuais são mais comuns em níveis socioeconômicos baixos e litigiosas em altos. Os dados indicam que o divórcio pode ser considerado uma crise vital contemporânea e demanda dos profissionais maior complexidade nas suas intervenções tanto de ordem jurídica como psicológica no fenômeno.
\end{abstract}

Palawasdhave D ivórcio; Estado civil; Status socioeconômico; Relações familiares.

\section{The profile of couples who experience consensual divorces and litigation: an analysis of lawsuits}

\begin{abstract}
This study aimed to identify the reasons, circumstances and consequences of marital dissolution from records in legal proceedings. A documentary analysis of 152 marital dissolutions archived from 1992 to 2006 in the Forum of a city in RS was performed. There was a descriptive and discriminant analysis of the data. The most cited reasons relate to marital conflict in its different hues and intensities. As for the outcome, it was found that $46.7 \%$ of cases were consensual, $30.9 \%$ litigation, $22.4 \%$ abandoned the lawsuit or have reconciled. The profile of the couples is mainly discriminated by socioeconomic level in relation to consensual processes or litigation. Consensual separations are more common in low socioeconomic levels and litigation in high. D ata indicate that divorce may be considered a contemporary life crisis that demands more complexity of professionals in their interventions both legal and psychological phenomenon.
\end{abstract}

Kegnads Divorce; Marital status; Socioeconomic status; Family relationship.

\section{El perfil de las parejas que expenimentan divorcios consensuales y litigiosos: un análisis de los litigios}

\begin{abstract}
Resumen
Este estudio tuvo como objetivo identificar las razones, circunstancias y consecuencias de las separaciones matrimoniales por medio de registros en procesos judiciales. Se realizó un análisis documental de 152 separaciones conyugales archivadas desde 1992 hasta 2006, en el Foro de una ciudad de RS-Brasil. Se hizo un análisis descriptivo y discriminante de datos. Los motivos más citados se refieren a conflictos de pareja en sus diferentes matices e intensidades. En cuanto a los resultados, se encontró que el 46,7\% de los casos fueron consensuales, el 30,9\% litigiosos, y en el 22,4\% de ellos hubo abandono de la acción o reconciliación. El perfil de las parejas es discriminado principalmente por el nivel socioeconómico en relación a los procesos consensuales o litigiosos. Separaciones consensuales son más frecuentes en niveles socioeconómicos más bajos y litigiosas en las altas. Los datos indican que el divorcio puede ser considerado como una crisis vital contemporánea y demanda de los profesionales una mayor complejidad en sus intervenciones tanto de orden jurídico como psicológico en el fenómeno.

Palabrasdave Divorcio; Estado civil; Status socioeconómico; Relaciones familiares.
\end{abstract}

No Brasil, os dados do censo do IBGE (2007) mostram que de 2001 a 2005 aumentou o número de casamentos, ao mesmo tempo em que as separações judiciais de 2005 tiveram um incremento de 7,4\%, em comparação com o ano de 2004. Essas evidências demonstram que as pessoas continuam considerando 0 casamento importante e, consequentemente, querendo casar-se. Entretanto, algumas características tradicionais das uniões como, por exemplo, a estabilidade e durabilidade da relação, não têm sido mais uma premissa básica do casamento. Haja vista a crescente diminuição das relações conjugais que duram "atéquea moteos sqpare".
A partir dessa premissa, pesquisas nacionais têm comprovado nos últimos anos que as uniões conjugais são múltiplas e a separação um fato recorrente (FéresCarneiro \& Magalhães, 2008; Heilborn, 2004; Wagner \& Mosmann, 2009). Entre os fatores que contribuíram para essas mudanças podemos citar diversas variáveis socioeconômico-culturais, que, através de um processo de constantes transformações, se expressam hoje em dia em um cenário onde as famílias e a sociedade em geral estão menos conservadoras, atribuindo menor valor ao caráter sagrado do casamento. As pessoas aceitam com maior naturalidade diferentes estilos de vida, que incluem ficar solteiro, viver com um parceiro de qualquer um dos sexos, divorciar-se, casar-se várias 
vezes e não ter filhos, por exemplo (Papalia, Olds \& Feldman, 2006). Soma-se a isso o fato de que os interesses pessoais tendem a ser mais valorizados que os conjugais na relação, isso é, observam-se relacionamentos marcados por demandas individuais, constatando-se uma tendência à sobreposição dos interesses individuais sobre os conjugais (Coelho, 2000; Heilborn, 2004; Pais, Cairns \& Pappámikail, 2005; Zordan, Falcke \& Wagner, 2009), havendo menos espaço e disponibilidade para compartilhar, dividir e socializar.

Em termos contextuais, esses aspectos repercutem na diminuição dos índices de natalidade, no aumento da profissionalização, da necessidade de independência econômica, da liberdade para o exercício da sexualidade para ambos os sexos fora de uma relação estável, entre outros. Nessa perspectiva também se observa, no cenário internacional, a desvinculação da reprodução do vínculo conjugal, havendo um aumento na incidência da maternidade voluntária fora do casamento, entre outros fatores (Carter \& McGoldrick, 2001; Gimeno, 1999; Heilborn, 1995, 2004; Jablonski, 1998, 2003; Paterniani, 1997).

Ante essas mudanças, uma primeira geração de pesquisas sobre o divórcio buscou compreender esse fenômeno, tentando identificar as razões predominantes que levam às separações conjugais. Os resultados de então apontam a ascensão do status feminino e o fato de ambos os cônjuges poderem ser igualmente bem-sucedidos (Carter \& McGoldrick, 2001). Também referem as diferenças em aspectoschave da vida familiar e pessoal, tais como valores, hábitos, interesses, o exercício de papéis familiares, a ruptura com a família extensa e 0 isolamento social (Gimeno, 1999), como aspectos relevantes na compreensão dos motivos para o divórcio.

Entretanto, sabe-se que o casamento implica uma dinâmica entre dois sujeitos, onde inúmeras variáveis se interseccionam, dessa forma não havendo como identificar apenas um motivo que leve à dissolução das uniões. Nesse sentido, uma segunda geração de pesquisas que foram desenvolvidas no Brasil nas áreas da Psicologia, Direito, Sociologia, Economia e Serviço Social têm demonstrado a natureza multifatorial da separação. Essas investigações identificam causas psicossociais que permeiam os conflitos conjugais e que levam à ruptura do vínculo matrimonial, associando os fatores psicológicos e destacando a influência da família de origem e do meio social sobre as pessoas que vivenciam o processo de separação (Jorge, 2003; Nogueira, 2006; Silva, 2001; Viegas, 2006).

Em se tratando das características pessoais dos cônjuges, a busca pela realização pessoal, o maior grau de exigência das mulheres economicamente independentes e o alcoolismo são identificados como causas frequentes. Especificamente em relação às mulheres a literatura aponta que elas tendem a encabeçar 0 pedido de separação (Carter \& McGoldrick, 2001; Féres-Carneiro, 1998; 2003), entretanto os desdobramentos desta iniciativa ainda não são conclusivos na literatura. Dados internacionais indicam que as mulheres com menor renda tendem a buscar mais divórcios litigiosos em comparação a mulheres com maior renda pessoal (Diniz \& FéresCarneiro, 2010). No contexto nacional, não há dados que permitam traçar este panorama. Cabe ressaltar que no Brasil a maior parte dos estudos sobre o divórcio refere-se à população de renda média e centra-se predominantemente nas repercussões do divórcio sobre os filhos (Cano, Gabarra, Moré \& Crepaldi, 2009).

No que se refere aos processos relacionais do casal, os estudos apontam como motivos a infidelidade, a incompatibilidade de gênios e o desgaste da dimensão amorosa (Goldenberg, 2000; Porreca, 2004; Viegas, 2006). E como preditores de separação conjugal Markman (2004) aponta os problemas de comunicação do casal, a intensidade dos conflitos e estratégias ineficazes de resolução.

Identifica-se neste cabedal de investigações que as razões são diversas e compreendem variáveis pessoais, contextuais e familiares. Isso se explica porque 0 relacionamento conjugal é dinâmico e de caráter multidimensional. Da mesma forma que a qualidade conjugal vivenciada pelos casais é resultado da conjunção de características pessoais, do meio onde se inserem e de seus processos adaptativos, a separação também resulta dessa intrincada teia de interações. Tal complexidade caracteriza o desafio de tentar desvelar os processos subjacentes que se expressam nos inúmeros motivos apontados pelos casais como foco de ruptura do vínculo.

Embora essa busca não se justifique mais por questões legais, já que a nova lei do divórcio, aprovada em 2010, permite o pedido de divórcio sem precisar da alegação de causas ou motivos, extingue o instituto da separação, elimina prazos e a busca pelo culpado pela dissolução da sociedade conjugal, o caráter cada vez mais corriqueiro que vêm assumindo os divórcios não implica menores repercussões emocionais decorrentes do fim das uniões. Sabe-se que não somente os cônjuges sofrem com esses processos. Seus filhos e suas famílias extensas se deparam com um processo doloroso que demanda uma reorganização de todo 0 sistema familiar (Sullivan, Pasch, Cornelius \& Cirigliano, 2004). 
Considerando os índices crescentes de novas uniões e as taxas mundiais estáveis de recasamento, que expõem o desejo permanente das pessoas de buscar uma união satisfatória, identifica-se a permanência desta problemática. Se os indivíduos seguem tentando relacionar-se sem sucesso, isso indica que eles simplesmente mudam de parceiro, mas os motivos que levaram ao fim a primeira união provavelmente virão a se repetir nas uniões sucessivas. Este processo indica a necessidade de desenvolver-se um trabalho que aponte alternativas de intervenções precoces com casais para que os mesmos obtenham recursos que os auxiliem na manutenção de seus relacionamentos com melhores índices de satisfação conjugal.

Nesse sentido, já está comprovado que se os casais recebem algum tipo de ajuda profissional antes dos primeiros cinco anos de união, sendo orientados sobre os fatores de risco do casamento e de como lidar com eles, apresentam menores índices de divórcio. Estas intervenções, chamadas de Educação Conjugal, são uma alternativa cada vez mais pungente nos dias atuais (Wagner \& Mosmann, 2011). Teoricamente esses programas se definem como treinamento preventivo/ educacional para casais. Esse tipo de intervenção visa engajar os cônjuges em processos de aprendizagem, reflexão, conscientização e treinamento de habilidades, no intuito de que estabeleçam relações com melhores níveis de saúde e estabilidade (Roberts, 2006).

Assumindo as possibilidades de preencher essas lacunas teóricas e interventivas com casais, torna-se de extrema relevância investigar os motivos alegados pelos cônjuges para a separação. Estudos nessa perspectiva podem gerar subsídios para o desenvolvimento de programas de prevenção e educação para a conjugalidade contextualizados à realidade brasileira.

Especificamente no que se refere ao nosso contexto, sabe-se que a maior parte dos casais com problemas não procura terapia conjugal, mas sim, muitas vezes, recursos na própria comunidade onde se insere, tais como a igreja, a escola e a rede social de apoio (Markman \& colaboradores, 2004). Nesse sentido, é fundamental para o desenvolvimento e a difusão desses programas que os motivos que venham a se constituir em focos de intervenção provenham não só dos consultórios, mas também de locais disponíveis na realidade dos sujeitos envolvidos, considerando as idiossincrasias de cada contexto. Neste panorama, 0 poder judiciário se caracteriza como celeiro dessas informações, uma vez que até a metade do ano de 2010, todos os pedidos de separação deveriam ser justificados pelo demandante, constituindo-se em um grande banco de dados acerca dos motivos alegados para o divórcio.
Dessa forma, o presente artigo apresenta os resultados de um estudo que buscou, por meio de uma análise documental, levantar os motivos, circunstâncias e contextos das separações conjugais a partir de registros em processos judiciais.

\section{Método}

Este foi um estudo do tipo exploratório e descritivo, de caráter quantitativo, realizado através de uma análise documental.

Os dados form coletados nos registros dos processos de separação conjugal do Fórum de uma cidade do interior do Rio Grande do Sul. Estes haviam sido arquivados no período de 1992 a 2006 e a coleta de dados foi realizada de julho a setembro de 2007.

Inicialmente foi feito um contato com a juíza de família da Comarca para expor o projeto, apresentar outros estudos semelhantes e solicitar a autorização para fazer o levantamento. A juíza da vara de família e o juiz diretor do Fórum permitiram o levantamento de dados mediante a assinatura de um termo de compromisso pelos responsáveis da pesquisa.

Após, foi realizada a leitura dos processos e foram coletados os dados pertinentes ao estudo, os quais foram registrados e organizados numa ficha criada para esse fim, a qual continha variáveis sociodemográficas (sexo, idade, escolaridade, profissão, nível socioeconômico), o tipo de ação judicial, as características da união conjugal, os motivos alegados para a separação/ dissolução e o desfecho do processo judicial.

Os dados foram coletados nos processos judiciais guardados em caixas no Arquivo do Fórum. As caixas continham todos os processos que haviam sido encerrados no período de 1992 a 2006 e estavam numeradas e identificadas quanto ao tipo de demanda. Do total de caixas, 40 estavam identificadas como contendo processos na área de família, havendo em cada caixa uma média de 10 processos relacionados ao tema da separação conjugal ou dissolução de união de fato.

A amostra deste estudo foi constituída pela primeira metade das caixas identificadas como contendo processos de família, segundo a numeração e ordenação das caixas na sala. D os processos de cada caixa, foram selecionados aqueles relacionados à separação conjugal e à dissolução de união estável. Nesta primeira seleção, chegou-se a um total de 180 processos referentes a separação conjugal ou dissolução de união de fato. Entretanto, 28 deles foram excluídos porque não preenchiam todos os critérios de inclusão, isto é, conter informações completas sobre 0 
tipo de ação, dados referentes à mulher, ao homem, ao casamento, à separação e o desfecho final do processo.

A partir desse processo seletivo, a amostra final ficou constituída por 152 processos de separações conjugais, classificados segundo o tipo de ação pela linguagem jurídica, em: litigiosos (69 casos, 45,4\%), consensuais (51 casos, 33,6\%) e dissoluções de uniões de fato (32 casos, 21,1\%). Em relação às dissoluções de uniões de fato os juristas não classificam em litigiosas ou consensuais.

\section{Resultados e discussão}

Foram realizadas análises descritivas para caracterizar a amostra e o levantamento dos motivos alegados para separação. Além disso, foi realizada uma análise discriminante para estabelecer um perfil dos casais quanto aos motivos alegados nos processos para a separação e as variáveis sociodemográficas que caracterizavam os sujeitos envolvidos. Para todas as análises foi considerado como significativo um valor de $\mathrm{p} \leq 0,05$.

O nível socioeconômico foi investigado de forma individual e não do casal, utilizando o critério de classificação de Hollingshead (1975), a partir do nível ocupacional e do nível de escolaridade. Encontraram-se na amostra pesquisada, quatro níveis socioeconômicos (NSE), sendo estes: baixo, médio-baixo, médio, médio- alto. No nível médio-alto foram agrupados dois extratos, o nível alto e o médio-alto, devido à baixa frequência de casos do nível alto (cinco casos entre as mulheres e quatro entre os homens). Constata-se que, no caso das mulheres, predominou 0 nível socioeconômico baixo $(64,0 \%)$, enquanto entre os homens houve maior concentração nos níveis baixo (41,3\%) e médio-baixo (32,7\%), totalizando 74,0\%.

Com a relação à esdaridade das mulheres, 9,3\% não possuíam estudo, $64,7 \%$ concluíram o ensino fundamental, 20,0\% concluíram o ensino médio e 6,0\% possuíam ensino superior. Já quanto aos homens, 6,7\% não possuíam estudo, 63,3\% concluíram o ensino fundamental, 24,7\% concluíram o ensino médio e 5,3\% tinham ensino superior. Portanto, nessa amostra, predomina o nível de ensino fundamental tanto para as mulheres quanto para os homens. Nesse sentido, observa-se que num cenário onde predominam estudos com casais de classe média (Cano \& cols., 2009), esses resultados revelam que o divórcio não é um fenômeno circunscrito a um determinado panorama socioeconômico-cultural, mas ocorre invariavelmente nos distintos estratos socioeconômicos.

No que se refere à variável profissão, levantamos a profissão da mulher e do homem exercida à época do casamento e aquela do momento da solicitação da separação, expressas na Tabela 1.

Tabela 1. Profissão das mulheres e dos homens ao casar e ao solicitar separação/ dissolução

\begin{tabular}{lccccc}
\hline \multirow{2}{*}{ Profissão } & \multicolumn{2}{c}{ Mulheres } & & \multicolumn{2}{c}{ Homens } \\
\cline { 2 - 3 } \cline { 5 - 6 } \cline { 5 - 6 } & Data casamento & Pedido separação nasamento & Pedido separação \\
\hline Dona de casa/ não trabalha fora & $44,4 \%$ & $33,5 \%$ & & $0 \%$ & $9,3 \%$ \\
Profissões ensino fundamental & $33,3 \%$ & $45,4 \%$ & & $76,1 \%$ & $66,8 \%$ \\
Profissões ensino médio & $16,0 \%$ & $14,5 \%$ & & $20,4 \%$ & $21,9 \%$ \\
Profissões ensino superior & $6,3 \%$ & $6,6 \%$ & & $3,5 \%$ & $2,0 \%$ \\
\hline Total & $100 \%$ & $100 \%$ & & $100 \%$ & $100 \%$ \\
\hline
\end{tabular}

Pode-se observar na tabela que, no grupo das mulheres, ocorreu uma mobilidade na atividade profissional entre o momento do casamento e a separação. Aparece um decréscimo na porcentagem das que se dedicavam às tarefas do lar (no casamento 44,4\%; na separação 33,5\%), assim como entre aquelas que tinham profissões de nível médio na data do casamento $(16,0 \%)$ e no pedido de separação $(14,5 \%)$. Ao mesmo tempo, observa-se um aumento, entre 0 peńodo do casamento e a separação, na porcentagem daquelas que exerciam atividades de nível fundamental (33,3\% para 45,4\%) e superior (6,3\% para 6,6\%). Identificase a partir desses resultados, uma ascensão das mulheres quanto às atividades remuneradas. Chama atenção o fato de haver diminuído os porcentuais daquelas que somente se dedicavam às tarefas do lar. Este resultado corrobora estudos internacionais que destacam a conquista de melhor status feminino como uma das vanáveis associadas ao divórcio, pois este é um aspecto que normalmente altera a dinâmica conjugal e, por vezes, pode resultar na ruptura do vínculo matrimonial (Carter \& McGoldrick, 2001).

Quanto ao grupo dos homens, a maior mobilidade aparece nas profissões de ensino fundamental entre a data do casamento (76,1\%) e a separação (66,8\%). Chama a atenção entre a população masculina a categonia "não exercem atividade remunerada fora do lar" a qual é contabilizada no peńodo da separação. Esse fato expressa 0 momento do ciclo vital em que ocorre a solicitação da separação, no caso, para os homens, a meia idade e, sendo assim, coincidindo com o peńodo de aposentadoria. A idade das mulheres ao casar variou de 14 a 52 anos e dos homens de 14 a 56 anos. Organizou-se a faixa etánia dos sujeitos pesquisados em três níveis, assim descritos: adolescência 
média: de 14 a 17 anos; adolescência final: de 18 a 24 anos; adultos: a partir dos 25 anos. Na Tabela 2, apresenta-se a porcentagem de casamento das mulheres e dos homens em cada grupo etário.

Tabela 2. Idade das mulheres e dos homens ao casar/ unir

\begin{tabular}{lrr}
\hline Idade em anos & Mulheres & Homens \\
\hline 14 a 17 & $22,8 \%$ & $2,4 \%$ \\
18 a 24 & $55,1 \%$ & $60,3 \%$ \\
25 em diante & $22,0 \%$ & $37,3 \%$ \\
\hline Total & $100,0 \%$ & $100,0 \%$ \\
\hline
\end{tabular}

Pode-se observar que a faixa etánia na qual predominou o início do casamento foi dos 18 aos 24 anos (adolescência final), tanto para as mulheres $(55,1 \%)$ como para os homens (60,3\%).

A idade, no momento da solicitação da separação, entre as mulheres variou de 18 a 70 anos e entre os homens de 20 a 71 anos. Para trabalhar com os dados, foram agnupados de 18 a 24 anos (adolescência final), de 25 a 40 anos (adultez jovem), de 41 a 60 anos (adultez média) e de 61 anos em diante (terceira idade). Na Tabela 3, apresenta-se a porcentagem de solicitação de separação das mulheres e dos homens em cada grupo etário. Observa-se que as faixas etánias onde predominou a separação foi dos 25 aos 40 e dos 41 aos 60 anos tanto para as mulheres como para os homens. Nessa amostra a separação dos casais se deu predominantemente na adultez jovem e na adultez média.

Tabela 3. Idade das mulheres e dos homens ao solicitar separação/ dissolução

\begin{tabular}{lcc}
\hline Idade em anos & Mulheres & Homens \\
\hline 18 a 24 & $11,3 \%$ & $5,1 \%$ \\
25 a 40 & $46,2 \%$ & $43,5 \%$ \\
41 a 60 & $40,4 \%$ & $47,1 \%$ \\
61 em diante & $2,1 \%$ & $4,3 \%$ \\
\hline Total & $100 \%$ & $100 \%$ \\
\hline
\end{tabular}

No que se refere ao tempo de casamento/ união no momento de solicitação da separação, agrupamos conforme o ciclo vital da família: de zero a sete anos (formação do casal e nascimento de filhos), oito a 21 anos (período de criação dos filhos) e de 22 anos em diante (saída de casa dos filhos) (Carter \& McGoldrick, 2001). Constatou-se que houve predomínio de separações no período de oito a 21 anos $(49,3 \%)$, seguido do período de zero a sete anos $(29,6 \%)$ e 21,1\% das solicitações de separação após 22 anos de união.

Quanto à variável "quem solicitou a separação/ dissolução", constatou-se a predominância feminina em 50,3\% dos casos. Foi solicitada por ambos em 33,8\% dos casos e pelo homem em 15,9\%. Esses achados corroboram pesquisas anteriores que encontraram que a grande demanda e a decisão da separação é feminina (Carter \& McGoldrick, 2001; Féres-Carneiro, 1998, 2003).

O regime de comunhão de bens adotado com maior frequência foi a comunhão parcial (58,3\%), sendo que $39,2 \%$ optaram pela comunhão universal e apenas 2,5\% pela separação total de bens. Nesse aspecto, é pertinente lembrar que a legislação brasileira adotava automaticamente a comunhão de bens universal até 1977, quando da aprovação da lei do divórcio. A partir daí o regime intrínseco ao laço conjugal é a separação parcial de bens. Assim, se um casal quiser adotar outro regime de bens deverá fazer um pacto pré-nupcial e registrá-lo em cartório e isso será registrado na certidão de casamento.

O utro aspecto que descreve a amostra de pessoas envolvidas no processo de separação/ divórcio é o fato de que $100 \%$ das mulheres tinham acrescentado 0 sobrenome do marido e 80,2\% solicitavam no processo de dissolução a substituição do nome de casada para voltar a usar o nome de solteira.

Quanto à variável filhos, $19,5 \%$ da amostra não tinha filhos. Entre os que tiveram filhos, 28,9\% tinha apenas um; $28,2 \%$, dois; $12,8 \%$, três; $6,0 \%$, quatro; e $4,7 \%$, cinco filhos ou mais. Um dado que chama atenção entre os que estavam casados oficialmente (120 casos) é a porcentagem (24,3\%) dos que tinham filhos gerados ou nascidos antes da oficialização do casamento, conforme certidões de nascimento e casamento anexas ao processo. Assim, pode-se pensar que casaram grávidos, o que pode ter motivado ou precipitado a oficialização da união.

Em relação ao(s) motivo(s) para separação, cabe salientar que foram colhidos pela informação registrada pelos advogados ao entrar com 0 pedido de separação/dissolução no Fórum e, portanto, com 0 
viés de quem quer defender a parte que o contratou. Considerando esse fato e, também, que a legislação brasileira não exige mais que sejam apresentados os motivos para separação/ dissolução, constatou-se que em $79,6 \%$ dos processos não havia registro do(s) motivo(s) para separação. Entre os que continham 59,2\% apresentavam apenas um motivo e 40,8\% registravam vários motivos. A Tabela 4 mostra a frequência e a porcentagem dos motivos alegados nos processos.

Tabela 4. Motivos alegados nos processos de separação conjugal

\begin{tabular}{lcc}
\hline Motivos & Frequência & Porcentagem \\
\hline Brigas e discussões frequentes & 44 & $28,9 \%$ \\
Agressões do cônjuge & 36 & $23,7 \%$ \\
Já estavam separados de fato & 35 & $23,0 \%$ \\
Alcoolismo do cônjuge & 29 & $19,1 \%$ \\
Agressões com envolvimento dos filhos & 21 & $13,8 \%$ \\
Abandono do lar pelo homem & 14 & $9,2 \%$ \\
Ameaça de morte & 13 & $8,6 \%$ \\
Não-cumprimento dos deveres do casamento* & 11 & $7,2 \%$ \\
Abandono do lar pela mulher & 4 & $2,6 \%$ \\
Outros fatores & 17 & $11,2 \%$ \\
\hline
\end{tabular}

Nota: *Na linguagem jurídica, os deveres do casamento são: fidelidade recíproca; vida em comum, no domicílio conjugal; mútua assistência; sustento, guarda e educação dos filhos; respeito e consideração mútuos (Código Civil, 2002).

Observa-se, nos dados coletados, que os motivos alegados são genéricos e pouco explicam a especificidade do conflito ou da dificuldade que levou à ruptura do vínculo conjugal. No entanto, entre os motivos mais frequentemente alegados, pode-se constatar que o conflito conjugal definido por uma oposição ostensiva entre cônjuges, identificada pelos mesmos como desentendimentos ou fonte de dificuldades no relacionamento (Markman, 2004), expresso aqui como brigas, discussões, agressões, quando não bem encaminhado, é 0 fator mais importante na explicação da ruptura do vínculo. Nesse sentido, contata-se a necessidade de favorecer que os casais desenvolvam estratégias de resolução de seus conflitos, já que este é um aspecto inerente às relações humanas.

Quanto às diversas formas de desfecho de tais conflitos, constatou-se nas demandas judiciais de separação que $46,7 \%$ dos processos foram consensuais, 30,9\% litigiosos e, em 22,4\%, houve abandono da ação ou reconciliação. $O$ fato de quase um quarto da amostra ter abandonado a ação ou se reconciliado é um dado que chama atenção, pois faz pensar a respeito da necessidade de um espaço onde as pessoas sejam ouvidas, consigam ouvir seu/sua parceiro/a, refletir e avaliar as suas dificuldades relacionais, assim como as motivações para a dissolução das uniões antes da audiência de conciliação proposta pelo juiz. Provavelmente, diante essa possibilidade, muitos casais repensassem suas decisões e pudessem retomar a relação de outra maneira, encaminhando melhor seus conflitos e ampliando o seu repertório de estratégias de enfrentamento dos mesmos.
A partir desses dados, tornou-se relevante obter um perfil entre os grupos que solicitaram separação conjugal consensual e litigiosa e, para tanto, utilizou-se a Análise Discriminante. 0 número de funções discriminantes é igual ao número de grupos menos um. Neste caso, tendo dois tipos de ação, identificaram-se dois grupos, explicados por uma função que respondeu por $100 \%$ da variância $(\mathrm{p}=0,000) . \quad \mathrm{A}$ análise discriminante utiliza uma variável de agrupação que maximiza a distância (diferença) entre os grupos, no caso que variáveis discriminam os grupos segundo os tipos de ação (Sarriera, 1996). As variáveis preditoras utilizadas foram: sexo, idade ao casar e ao solicitar a separação, escolaridade, profissão ao casar e ao solicitar a separação, ascensão ou descenso profissional, nível socioeconômico atual, tempo de casamento/ união, número de filhos, separação solicitada por quem, tipo de desfecho, número de motivos. Essas variáveis foram selecionadas por terem sido apontadas como motivos para a separação conjugal em estudos brasileiros (Goldenberg, 2000; Lopes, 2006).

0 grupo da separação consensual discrimina-se pelas seguintes variáveis: a separação ter sido solicitada pela mulher $(0,758)$, o nível socioeconômico da mulher $(0,254)$ e do homem ser baixo ou médio-baixo $(0,177)$, a escolaridade da mulher $(0,234)$ e do homem $(0,195)$ ter sido até 0 ensino fundamental e a comunhão parcial como regime de bens $(0,087)$. Já o grupo da separação litigiosa perfila-se pelas variáveis: idade da mulher no momento da separação $(-0,268), 0$ casamento ter durado entre oito e 21 anos $(-0,217)$, ter entre um e dois filhos $(-0,222)$, idade do homem no momento da separação $(-0,175)$, casal alegar mais de um motivo para 
a separação $(-0,171)$, idade ao casar da mulher $(-0,090)$ e do homem $(0,006)$ entre os 18 e 24 anos, o fato dos homens $(-0,027)$ e das mulheres $(-0,006)$ permanecerem na sua profissão ao longo do casamento.

0 fato das correlações entre as variáveis e a função discriminante serem positivas ou negativas não é mais relevante do que 0 poder explicativo das mesmas, sendo as variáveis que apresentaram médio poder explicativo estatisticamente definidas acima de 0,30 (Sarriera, 1996) e assim sucessivamente.
Além das variáveis preditoras associadas à função discriminante, estatisticamente é bastante relevante saber qual é a capacidade final dessa função para classificar corretamente os sujeitos no seu grupo correspondente (Sarriera, 1996). Isso fica evidenciado na Tabela 5 , onde a classificação obtida do perfil discriminante consegue predizer corretamente 89,6\% dos casos das separações consensuais e 100\% dos casos das separações litigiosas.

Tabela 5. Preditores de grupo consensual e litigioso: classificação de resultados

\begin{tabular}{|c|c|c|c|c|c|c|}
\hline \multirow{3}{*}{ Tipos de ação } & \multicolumn{6}{|c|}{ Membros do grupo preditor } \\
\hline & \multicolumn{2}{|c|}{ Consensual } & \multicolumn{2}{|c|}{ Litigiosa } & \multicolumn{2}{|c|}{ Total } \\
\hline & $\mathrm{N}$ & $\%$ & $\mathrm{~N}$ & $\%$ & $\mathrm{~N}$ & $\%$ \\
\hline Consensual & 43 & 89,6 & 5 & 10,4 & 48 & 100,0 \\
\hline Litigiosa & 0 & 0,0 & 67 & 100,0 & 67 & 100,0 \\
\hline Casos não agrupados & 3 & 33,3 & 6 & 66,7 & 9 & 100,0 \\
\hline
\end{tabular}

Nota: 95,7\% casos classificados corretamente do grupo original.

Dessa forma, identificou-se nos processos analisados que os sujeitos envolvidos em separações consensuais têm um perfil que é definido por ser normalmente a mulher quem toma a iniciativa, sendo que ambos têm ensino fundamental e pertencem ao nível socioeconômico baixo e médio-baixo, tendo estado casados em regime de comunhão parcial de bens.

Por outro lado, as características que definem 0 perfil dos sujeitos envolvidos em processos litigiosos são mulheres e homens adultos (entre 25 e 60 anos) que se casaram no final da adolescência, tiveram entre um e dois filhos, tendo permanecido casados entre oito e 21 anos e que apresentam mais de um motivo para separação.

O perfil associado ao divórcio consensual corrobora achados de pesquisas nacionais, os quais afirmam que as mulheres sofrem maior influência dos aspectos econômicos, tanto na hora de iniciar como de romper uma relação, acrescentando ainda a ideia de que elas apresentam maior propensão para inaugurar 0 movimento de saída de um relacionamento do que os homens (Sachsida, Loureiro, Mendonça \& Sachsida, 2003).

Esse resultado é consenso na literatura nacional e internacional. Entretanto, nossos perfis agregam um dado extremamente relevante ao mostrar que características possuem as mulheres que empregam um divórcio consensual e as que enfrentam o litígio judicial. As mulheres, da nossa amostra, com menor renda e nível de ensino fundamental tendem a resolver os desdobramentos da separação sem a necessidade de intervenção judicial. Morgan (1988) aponta que o nível educacional mais baixo estaria mais associado à possibilidade de reconciliação, uma vez que a mulher poderia sentir-se com poucos recursos pessoais para lidar com o complexo processo do divórcio litigioso. Soma-se a isso o fato de estas pessoas terem menor conhecimento de seus direitos e maior dificuldade de dispor de recursos para arcar com os custos de um processo litigioso. De alguma maneira parece que essas mulheres tomam a iniciativa em separar-se, mas se resignam com o rumo definido pelo companheiro.

Por outro lado, o perfil associado ao divórcio litigioso é definido pela presença de filhos e maior tempo de união. A preocupação com a segurança e 0 sustento dos filhos parece ser um fator relevante que leva à legalização da ruptura e, portanto, à oficialização judicial da corresponsabilidade paterna e materna no sustento da prole. Sabe-se que o pagamento da pensão alimentícia e a manutenção de uma relação próxima aos filhos após o divórcio, por ambos os genitores, indica a qualidade do vínculo não somente com a prole, mas com o ex-cônjuge (Pereira \& Pinto, 2003).

Nesse sentido, identifica-se que quanto mais independente economicamente é a mulher, mais exigente ela se torna com o seu parceiro amoroso, e 0 casamento não ocupa mais um lugar sagrado, quando "acaba 0 amor". Nesse caso, a independência econômica do marido libera a mulher para que possa considerar outros aspectos que definem a qualidade e a satisfação conjugal. Desse modo, tendem a não submeterem-se a permanecer em uma união pouco satisfatória, assim como também não hesitam em levar ao judiciário seus impasses com 0 ex-cônjuge, especialmente quando existem filhos envolvidos. 


\section{Considerações finais}

Com base nesses resultados, constatou-se que a separação conjugal na contemporaneidade é um fenômeno que pode ocorrer em qualquer etapa do ciclo vital do indivíduo, do casal e da família, com cônjuges que tenham tido filhos ou não, que tenham oficializado sua relação ou não, com casais que exerçam papeis tradicionais, sendo o homem provedor e a mulher dona de casa, ou casais de dupla renda, de dupla carreira. Nessa perspectiva, constata-se que este fenômeno não está restrito a um grupo específico de características sociodemográficas, podendo, também por isso, ser considerado uma crise vital.

A constatação de que as uniões não são mais obrigatoriamente para toda a vida, mas sim que podem ser rompidas a qualquer momento, faz atualmente do casamento um vínculo vulnerável, como qualquer outro. Este aspecto, dependendo das pessoas envolvidas na relação, pode tanto levar a um maior investimento na manutenção dessa união, como também levar a um menor comprometimento sustentado na ideia de que há sempre a possibilidade de novas uniões que poderão ser melhores do que a atual. Entretanto, a discussão contemporânea parece não se centrar mais no acontecimento do divórcio, mas nos desdobramentos do mesmo. Sabe-se das repercussões emocionais deste processo tanto para os cônjuges quanto para os filhos. Nesse sentido, nossos achados apontam perspectivas interessantes ao mostrar que as mulheres tomam mais a iniciativa para romper com as relações, mas também assumem as consequências de um divórcio litigioso, se isso envolver o bem-estar de seus filhos.

Independente da forma de encaminhamento da separação, é notável que os motivos alegados refiramse primordialmente aos conflitos em seus distintos níveis e matizes. Isso reforça a necessidade de intervenções preventivas com os casais visando ao desenvolvimento de habilidades para a resolução de seus conflitos, especialmente propostas acessíveis a toda a população, abrangendo diferentes níveis socioeconômico-culturais. Essas iniciativas poderiam proporcionar outros caminhos para as separações que não dependesse somente dos operadores do direito, os quais, sozinhos, não têm como dar conta e acessar toda a complexidade emocional envolvida nesses processos. Nesses casos, observa-se que, muitas vezes, a interminável demanda dos clientes por recursos legais ao longo do processo acabam por contribuir para que os divórcios litigiosos sejam muito prolongados e terminem se tornando uma transposição dos conflitos conjugais para 0 ambiente judicial. A mediação familiar vem sendo realizada em vários contextos em nosso país, quando o litígio já está instalado, com o propósito de favorecer a negociação entre os ex-cônjuges e de promover uma aliança no cuidado dos filhos. No entanto, não temos instituída e sistematizada uma prática preventiva que auxilie os casais antes de que se inicie o litígio.

Desde a aprovação da lei do divórcio, há mais de três décadas, a ruptura em si já não é o foco das preocupações daqueles que trabalham com esse fenômeno, mas sim a complexidade envolvida nesse processo que se desenvolve entre o conflito, a ruptura e o desdobramento. Para ampliar este conhecimento, estudos futuros poderão investigar os motivos, as circunstâncias e os contextos que envolveram a separação conjugal diretamente com as pessoas que a vivenciaram. Esses resultados também poderão contribuir para a identificação de alternativas de manutenção de relações mais saudáveis, mesmo após a desvinculação conjugal, pois este é, talvez, um dos desafios mais instigantes que temos a enfrentar.

\section{Referências}

Brasil. Lei $\mathrm{n}^{0}$ 10.406, de 10 de janeiro de 2002. Institui o Código Civil. Diáno Ofical [da] República Federativa do Brasil. Brasília-DF. Recuperado: 15, abril, $2012 . \quad$ Disponível: http:/ / www.in.gov.br/ visualiza/ index.jsp?data=1 1/ 01/ 2002\&jornal=1\&pagina=58\& totalArquivos $=192$.

Cano, D. S., Gabarra, L. M., Moré, C. O., \& Crepaldi, M. A. (2009). As transições familiares do divórcio ao recasamento no contexto brasileiro. Psicdoga: RellexãoeCńtica, 22(2), 214-222.

Carter, B., \& McGoldrick, M. (2001). As mudanças no ado de vida familiar. uma estutura para a terapia familiar. Porto Alegre: Artmed.

Coelho, S. V. (2000). As transformações da família no contexto brasileiro: uma perspectiva das relações de gênero. Psique, 10(16), 7-24.

Diniz Neto, O., \& Féres-Carneiro, T. (2010). Construção e dissolução da conjugalidade: padrões relacionais. Paidêa (RiberãoPreto), 20(46), 269-278.

Féres-Carneiro, T. (1998). Casamento contemporâneo: 0 difícil convívio da individualidade com a conjugalidade. Psicooga: Reflexão e Crítica, 11(2), 379-394.

Féres-Carneiro, T. (2003). Separação: 0 doloroso processo de dissolução da conjugalidade. Estudos de Psicologa, 8(3), 367-374. 
Féres-Carneiro, T., \& Magalhães, A. S. (2008). Novas configurações familiares e as repercussões em psicoterapia de família. Reista Brasilera de Psicoterapia, 10(2), 237-250.

Gimeno, A. (1999). La familia: d desafío dela diversidad Barcelona: Ariel.

Goldenberg, M. (O rg.). (2000). Osnovos desgos seis visães sobreas mudanças decompatameto dehomens emulheres na altura brasileira contemparâne. Rio de Janeiro: Record.

Heilborn, M. L. (1995). O que faz um casal, casal? Conjugalidade, igualitarismo e identidade sexual em camadas médias e urbanas. Em I. Ribeiro \& A. C. Ribeiro (O rgs.), Famlia em processos contemporâness inovaçás alturais na soiedade contemporâne (pp. 91-124). São Paulo: Loyola.

Heilborn, M. L. (2004). Dais é par. gênero e identidade sexual em contexto igualitánio Rio de Janeiro: Garamond.

Hollingshead, A. B. (1975). Far factor index of soial status Department of Sociology, Yale University, unpublished working paper.

IBGE (2007). Instituto Brasileiro deGeografia eEstatística. Recuperado: 15, junho, 2007. Disponível: http:/ / www.ibge.gov.br/ home/ eststistica/ popula cao/ acessoainternet.

Jablonski, B. (1998). A té quea vida nos œpare a cise db casamento contemparânea Rio de Janeiro: Agir.

Jablonski, B. (2003). Afinal, o que quer um casal? Algumas considerações sobre o casamento e a separação na classe média carioca. Em T. FéresCarneiro (O rg.), Famlia e casal: ananjos edemandas contemparânes(pp. 141-168). São Paulo: Loyola.

Jorge, M. M. (2003). Separaçãoconjuggl emfamílias debaixa renda (Dissertação de Mestrado). Universidade de São Paulo, São Paulo, Brasil.

Lopes, N. A. (2006). Casamento dissdução canjugal esuas funçás adaptativas (Dissertação de Mestrado). Universidade Federal do Rio Grande do Norte, Rio Grande do Norte, Brasil.

Markman, H. J. (2004). Couples research \& practice: toward a Bolder Boulder Model. The Family Psychdogist, 19(4), 4-6.

Markman, H. J., Whitton, S. W., Kline, G. H., Stanley, S. M., Thompson, H., St. Peters, M., Leber, D. B., Olmos-Gallo, A. P., Prado, L., Williams, T., Gilbert, K., Tonelli, L., Bobulinski, M., \& Cordova, A. (2004). Use of an empirically based marriage education program by religious organizations: results of a dissemination trial. FamilyRdations, 53, 504-512.

Morgan, L. A. (1988). O utcomes of marital separation: a longitudinal test of predictors. Jaumal of Mamage andFamily, 50, 493-498.

Nogueira, C. S. S. (2006). Novas fomas de lidar com o prowso da sqparação conjuggl ma modemidade líquida (Dissertação de Mestrado). Pontifícia Universidade Católica de Minas G erais, Minas Gerais, Brasil.

Pais, J. M., Cairns, D ., \& Pappámikail, L. (2005). Jovens europeus: retrato da diversidade. Tempo Sodal, 17(2), 109-140.

Papalia, D., Olds, S., \& Feldman, R. (2006). Desendvimentohumano Porto Alegre: Artmed.

Paterniani, A. L. S. (1997). A aventura amorosa do casal contemporâneo. Reista da Sociedade Brasileira deSexualidadeHumana, 8(1), 46-60.

Pereira, M. G., \& Pinto, H. (2003). O conflito no contexto da separação e divórcio: a perspectiva feminina. Psidợa: Tẹia, Investigação e Prática, 2, 187-203.

Porreca, W. (2004). Famílias recompostas casais catdicos em seyunda união (Dissertação de Mestrado). Universidade de São Paulo, São Paulo, Brasil.

Roberts, T. W. (2006). Marriage education and neuroscience: forging news directions. Joumal of Cauple\& Rdationship Therapy, 5(3), 17-33.

Sachsida, L. B., Loureiro, P. R. A., Mendonça, M. J. C., \& Sachsida, A. (2003). Fatores econônios deteminam o fim de uma reação conjugal. Recuperado: 6, junho, 2008.

Disponível: http:/ / www.anpec.org.br/ encontro2003/ artigos.

Sarriera, J. C. (1996). Introdurão à análise miltivaniada em psiđdøaja Pós-Graduação em Psicologia. Universidade Federal do Espírito Santo.

Silva, C. E. V. (2001). Sem "nós" das, o queresta sau "eu": os caminhos da saparação conjugal (Tese de Doutorado). Pontifícia Universidade Católica do Rio de Janeiro, Rio de Janeiro, Brasil.

Sullivan, K. T., Pasch, L. A., Cornelius, T., \& Cirigliano, E. (2004). Predicting participation in premarital prevention programs: the health belief model and social norms. Family Process, 43(2), 175193.

Viegas, I. L. F. (2006). A dessinalação ammosa na relação conjugal (Dissertação de Mestrado). Universidade de São Marcos, São Paulo, Brasil. 
Wagner, A., \& Mosmann, C. (2009). La familia reecnstituida, situaión y pespetivas pessonalidad, madure humana y contexto familiar (1 1 a ed.). Madrid: CCS.

Wagner, A., \& Mosmann, C. (2011). Educar para a conjugalidade: que a vida não nos separe. Em L. C. O sório \& M. E. P. Valle (Org.), Manual de terapia familiar (1 1 ed., v. 2, pp. 261-270). Porto Alegre: Artmed.
Zordan, E. P., Falcke, D., \& Wagner, A. (2009). Casar ou não casar? Motivos e expectativas com relação ao casamento. Psicloga em Reista (Online), 15(2), 56-76.
Reedidbem12/ 09/2011
Reamiladbem08/ 05/2012
Aproadb em20/ 06/2012

Sobre as autoras:

Eliana Piccoli Zordan é psicóloga clínica, psicoterapeuta sistêmica, mestre em Psicologia Clínica e doutora em Psicologia/ PUCRS. Coordenadora do Núcleo de Estudos e Pesquisa sobre Conjugalidades e Famílias (NEPECONFAM), é professora e supervisora de Estágios do Curso de Psicologia da Universidade Regional Integrada do Alto Uruguai e das Missões - URI - Campus de Erechim - RS.

Adriana Wagner é psicóloga, doutora em Psicologia Social pela Universidad Autonoma de Madrid, especialista em Terapia de Família e Casal na Escuela de Formación en Terapia Familiar - STIRPE (Espanha) professora adjunta do Instituto de Psicologia e do Programa de Pós-G raduação em Psicologia da UFRGS e coordenadora do Núcleo de Pesquisa Dinâmica das Relações Familiares (www.ufrgs.br/ relacoesfamiliares).

Clarisse Mosmann é psicóloga, doutora em Psicologia pela Pontifícia Universidade Católica do Rio Grande do Sul (PUCRS), especialista em Terapia de Casal e Família pela Escuela de Formación en Terapia Familiar - STIRPE, Espanha e professora do Programa de Pós-Graduação e do Curso de Psicologia da Universidade do Vale do Rio dos Sinos (UNISINOS).

Contato com as autoras:

Universidade Regional Integrada do Alto Uruguai e das Missões, Departamento de Ciências Humanas, Curso de Psicologia. Av. 7 de setembro n 1621, Centro. CEP 99700-000. Erechim, RS - Brasil.

E-mail: epzordan@ uricer.edu.br 